\title{
The Roles of BDNF in the Pathophysiology of Major Depression and in Antidepressant Treatment
}

\author{
Bun-Hee Lee and Yong-Ku Kim $\bowtie$ \\ Department of Psychiatry, College of Medicine, Korea University, Seoul, Korea
}

\begin{abstract}
Neurotrophic factors are critical regulators of the formation and plasticity of neuronal networks. Brain-derived neurotrophic factor (BD$\mathrm{NF}$ ) is abundant in the brain and periphery, and is found in both human serum and plasma. Animal studies have demonstrated that stress reduces BDNF expression or activity in the hippocampus and that this reduction can be prevented by treatment with antidepressant drugs. A similar change in BDNF activity occurs in the brain of patients with major depression disorder (MDD). Recently, clinical studies have indicated that serum or plasma BDNF levels are decreased in untreated MDD patients. Antidepressant treatment for at least four weeks can restore the decreased BDNF function up to the normal value. Therefore, MDD is associated with impaired neuronal plasticity. Suicidal behavior can be a consequence of severe impaired neuronal plasticity in the brain. Antidepressant treatment promotes increased BDNF activity as well as several forms of neuronal plasticity, including neurogenesis, synaptogenesis and neuronal maturation. BDNF could also play an important role in the modulation of neuronal networks. Such a neuronal plastic change can positively influence mood or recover depressed mood. These alterations of BDNF levels or neuronal plasticity in MDD patients before and after antidepressant treatment can be measured through the examination of serum or plasma BDNF concentrations. BDNF levels can therefore be useful markers for clinical response or improvement of depressive symptoms, but they are not diagnostic markers of major depression.

Psychiatry Investig 2010;7:231-235
\end{abstract}

Key Words Brain-derived neurotrophic factor, Neuroplasticity, Depression, Antidepressant.

\section{INTRODUCTION}

Major depressive disorder (MDD) is a common psychiatric mood disorder; mood disorders are episodic illnesses. MDDs consist of a single episode or several instances of recurrent or relapsed episodes of major depression. The pathophysiology of major depression can involve reversible changes. Recent reports have proposed that major depressive episodes and any subsequen recovery are associated with neuronal plasticity. Preclinical and clinical studies demonstrate that reductions of the total volume of neurons and neuronal loss occur in stress and depression in the adult hippocampus. ${ }^{1}$ These hippocampal alterations can be reversed by chronic antidepressant treatment. ${ }^{1}$ The associated neuronal plasticity involves actions of neurotrophic factors, such as brain-derived neurotrophic factor (BDNF).

Received: July 9, 2010 Accepted: September 7, 2010

Available online: November 23, 2010

$\triangle$ Correspondence: Yong-Ku Kim, MD

Department of Psychiatry, College of Medicine, Korea University, Ansan Hospital, 516 Gojan-dong, Ansan 425-020, Korea

Tel: +82-31-412-5140, Fax: +82-31-412-5144, E-mail: yongku@korea.ac.kr

@ This is an Open Access article distributed under the terms of the Creative Commons Attribution Non-Commercial License (http://creativecommons.org/licenses/bync/3.0) which permits unrestricted non-commercial use, distribution, and reproduction in any medium, provided the original work is properly cited.
BDNF is an important neurotrophic factor. Its function is mediated by its binding to specific receptors, such as the TrkB receptor among the tropomycin receptor kinase (Trk) family of tyrosine kinase receptors and the pan75 neurotrophin receptor $\left(\mathrm{p} 75^{\mathrm{NTR}}\right)$. Neurotrophic factors act in the activity-dependent manner of a neuronal network. BDNF expression is closely regulated by neuronal activity. ${ }^{2}$ Localization of the TrkB receptor also increases at synaptic sites after neuronal activity. ${ }^{3}$ $\mathrm{p} 75^{\mathrm{NTR}}$ is a low-affinity receptor of BDNF, and it can mediate neuronal apoptosis only when the Trk receptor is less active or not active. ${ }^{4}$

The neurotrophic hypothesis of depression proposes that depression is associated with reduced brain BDNF levels and that antidepressant treatments alleviate depressive behavior and increase BDNF levels. ${ }^{5}$ This alteration was recently explained as activity-dependent neuronal plasticity. ${ }^{6}$ In this study, we focused on recent findings regarding the role of BDNF in the occurrence and improvement of MDD and suicide, and we summarized findings of blood cell studies of BDNF.

\section{BDNF AND STRESS IN ANIMAL STUDIES}

Animal studies have shown that BDNF expression is dys- 
regulated by stress. Several types of stressors, including immobilization stress, foot shocks, social defeat, and early maternal deprivation, significantly decrease BDNF expression in the hippocampus, especially in the dentate gyrus. ${ }^{7-11}$ In particular, stressors such as forced swimming reduced BDNF messenger RNA (mRNA) in the hippocampus, and the physical activity-antidepressant treatment combinations enhanced swimming time and increased BDNF mRNA in an animal model. ${ }^{12}$

Several studies have found that exogenous corticosterone treatment reduces hippocampal BDNF expression. ${ }^{13,14}$ In contrast, adrenalectomy increases the level of BDNF in the hippocampus. ${ }^{15}$ These findings indicate that hippocampal BDNF expression is regulated via glucocorticoids. Moreover, antidepressant treatments can prevent stress-induced reduction of $\mathrm{BD}$ $\mathrm{NF}^{16}$ and they can restore the corticosterone-mediated decrease in BDNF expression. ${ }^{14}$ Therefore, stressors stimulate the activity of the hypothalamic-pituitary-adrenal axis, and then glucocorticoids increase, which can reduce the activity of BDNF.

\section{BDNF AND ANTIDEPRESSANT TREATMENT IN ANIMAL STUDIES}

Several classes of antidepressants, including monoamine oxidase inhibitors (MAOIs), selective serotonin reuptake inhibitors (SSRIs), tricyclic agents (TCAs), serotonin-norepinephrine reuptake inhibitors (SNRIs), and noradrenergic and specific serotonergic antidepressants, increase BDNF expression in the brain when given to healthy rodents. ${ }^{17}$ Electroconvulsive shock (ECS) and transcranial magnetic stimulation also increase the expression of BDNF in the rodent brain. ${ }^{18,19}$ Another experiment investigated the effects of acute and chronic treatment with different antidepressant agents and ECS on protein levels of BDNF in several brain regions of the rat. ${ }^{20}$ Chronic (21 days) but not acute (1 day) antidepressant treatment with TCAs, SSRIs and MAOIs increased BDNF levels in the frontal cortex by $10-30 \%$. Chronic MAOI use increased BDNF to a greater extent than treatment with the other classes of agents. Repeated daily treatments (10 days) of ECS enhanced BDNF levels in the hippocampus and frontal cortex by $40-100 \%$, but one ECS treatment (1 day) was not as effective. ${ }^{20}$ However, the effect of ECS was higher in magnitude compared to the effects of several antidepressant drugs. Various factors that influence this antidepressant effect on BDNF include length of administration, route of administration, class of antidepressant, and doses of the drugs. In general, increases in BDNF expression appear only after long-term treatment with antidepressants. ${ }^{21-23}$

Chronic antidepressant administration may induce plastic changes in the forebrains of rodents. ${ }^{17}$ Antidepressant treatments can also increase neurogenesis and synaptogenesis in the hippocampus. ${ }^{1,24}$ Chronic antidepressant treatment additionally increases the expression of plasticity-related proteins, including phosphorylated the cyclic adenosine monophosphate response element binding protein (CREB) and polysialylated neural cell adhesion molecules, in the hippocampus and prefrontal cortex..$^{25}$ These findings indicate that antidepressant treatment can increase neuronal plasticity in the brain.

Antidepressant treatment can also modulate chromatin remodeling, which regulates the activity of gene transcription. When histone subunits surround chromosomal DNA, methylation of histone subunits reduces gene transcription, whereas their acetylation enhances transcription. Antidepressant treatment can induce acetylation of histone subunits around the BD$\mathrm{NF}$ gene promoter region and lead to increased BDNF gene transcription and increased BDNF production. ${ }^{16}$

Wild-type mice that were given antidepressant agents experienced increased phosphorylation of CREB as well as phosphorylation of TrkB in the brain. ${ }^{26}$ When antidepressants were given to BDNF-deficient mice or Trk-defective mice, activations of CREB and Trk were reduced in BDNF-deficient or Trkdefective mice. In addition, the behavioral effects of antidepressants did not occur in BDNF-deficient mice or Trk-defective mice. ${ }^{26,27}$ BDNF-deficient mice have $50 \%$ lower forebrain BDNF mRNA and protein levels than the wild type mice. ${ }^{28} \mathrm{How}$ ever, BDNF-deficient mice do not have reduced activity or response to the forced swim test compared to the wild-type mice. ${ }^{29}$ Trk-defective mice also do not exhibit depression-like behaviors. ${ }^{30}$ Therefore, a deficiency or dysfunction of BDNF or the Trk receptor cannot induce depressed mood or behavior; BDNF itself does not control mood. However, the antidepressant response clearly requires an increase of BDNF activity and recovery of the neuronal network. A neuronal plastic change could positively influence mood or recover depressed mood. BDNF could also play an important role in the modulation of neuronal networks.

\section{BDNF AND MAJOR DEPRESSION IN CLINICAL STUDIES}

Previous human postmortem studies showed decreased BDNF expression or CREB immunoreactivity in the brains of participants with major depression who had not been treated with antidepressants, but those who were treated with antidepressant drugs had increased BDNF expression and CREB in the brain. ${ }^{31,32}$ These data are consistent with those of the aforementioned animal studies.

Recent clinical studies have explored serum or plasma BDNF levels in patients with major depression. Though the source of the circulating BDNF is not clear, BDNF is found in both human serum and plasma, and a large amount of the circulating $\mathrm{BDNF}$ is stored in human platelets as well. ${ }^{33} \mathrm{BDNF}$ can cross 
the blood-brain barrier in both directions, and the circulating BDNF could originate from neurons of the brain. ${ }^{34,35}$ Some clinical studies that measured serum BDNF levels in drug-free MDD patients have shown that serum BDNF levels are significantly lower in MDD patients than in healthy participants. ${ }^{36-39}$ Other studies reported that plasma BDNF levels are lower in drug-free MDD patients. ${ }^{38,40}$ However, there have been inconsistent findings of the relationship between BDNF levels and the severity of depression from these data. Some studies suggested a more significant decrease of BDNF in more severe depression. Though our data did not demonstrate any relationship between BDNF and depression severity, we found that relapsed or recurrent-episode MDD patients had much lower plasma BDNF levels than first-onset ones. ${ }^{40}$

Many clinical studies have evaluated the changes of plasma or serum BDNF levels before and after antidepressant treatments among MDD patients. Most studies reported increases of BDNF levels after antidepressant treatment. ${ }^{41}$ Two studies observed that both SSRI and SNRI treatments for eight weeks increased serum BDNF levels in MDD patients. ${ }^{36,42}$ However, another study reported that SSRI agents increased serum BDNF levels after six months, but that the SNRI agent did not change the level of BDNF even after six months of treatment. ${ }^{43}$ Additional clinical reports found that plasma and serum BDNF levels in MDD patients increased after six or eight weeks of antidepressant drug treatments. ${ }^{42,44}$ These studies suggest that the antidepressant-induced increase in BDNF level is more prominent in the responders to treatment rather than the non-responders. ${ }^{42,44} \mathrm{~A}$ meta-analysis indicated that post-treatment $\mathrm{BD}$ NF levels may be useful since four to eight weeks of antidepressant treatment are recommended to evaluate a change of BDNF or a treatment effect. ${ }^{41}$ Another recent study investigated changes of serum and plasma from MDD patients at baseline and following the first, third, sixth, and twelfth month of antidepressant treatment. ${ }^{45} \mathrm{MDD}$ patients had lower serum and plasma BDNF levels before treatment. Plasma BDNF increased in parallel with the clinical improvement from the one-month evaluation, while serum BDNF had no change after treatments.

These data of clinical studies of antidepressant treatment are consistent with those of animal studies on the effects of antidepressants on BDNF changes. Therefore, it is possible that serum or plasma levels of BDNF reflect the state of the neuronal network in patients with major depression. MDD patients can have decreased BDNF levels before treatment, which can be restored to the normal level through antidepressant treatment or by improving neuronal plasticity.

\section{BDNF AND SUICIDAL BEHAVIOR}

Postmortem studies show that mRNA expression and pro- tein levels of BDNF are reduced in the brains of patients with major depression who commit suicide. ${ }^{46,47}$ The expression of full-length $\operatorname{TrkB}$ or truncated $\operatorname{TrkB}$ (TrkB.T1) is significantly decreased in the brains of suicide patients in postmortem studies. ${ }^{47,48} \mathrm{~A}$ recent study observed decreased phosphorylation of Trk receptors and increased expression ratios of $\mathrm{p} 75^{\mathrm{NTR}}$ to Trks in the suicide patient's brain. ${ }^{49}$ These changes were particularly apparent in the prefrontal cortex and the hippocampus.

Clinical studies have examined BDNF levels in serum or plasma of MDD patients who have or have not attempted suicide. MDD patients who attempted suicide had lower serum BDNF levels than healthy controls. ${ }^{50}$ Our study found that plasma BDNF was significantly lower in suicidal MDD patients than in non-suicidal ones. ${ }^{40,51}$ Moreover, suicidal patients had the lowest levels of BDNF of all participants. ${ }^{40}$ We failed to find any correlation between BDNF level and the lethality of suicide. ${ }^{51}$ Dawood et al. ${ }^{52}$ took direct blood samples from the internal jugular vein and the brachial artery and then defined the veno-arterial BDNF plasma concentration gradient as an index of brain BDNF production. Their data showed a significantly decreased veno-arterial BDNF concentration gradient in patients at higher suicide risk among MDD participants.

These changes of serum or plasma BDNF levels in suicide patients are consistent with BDNF changes of the brain in postmortem studies on patients who died following suicide. Therefore, the phenomenon of suicidal behavior could be a consequence of a severe dysfunction of the neuronal network or of severely impaired neuronal plasticity in the brain compared to MDD patients.

\section{CONCLUSIONS}

BDNF is involved in activity-dependent neuronal plasticity, such as learning and memory ${ }^{53}$ Although animal studies clearly demonstrate that a decline of BDNF does not produce depressed mood or behavior, evidence from clinical studies tells us that decreased activity of BDNF or a neuronal dysfunction occurs in the brain of patients with major depression. Major depression is associated with impaired neuronal plasticity. Suicidal behavior can be a consequence of severely impaired neuronal plasticity in the brain. Antidepressant treatments promote several forms of neuronal plasticity, including neurogenesis, synaptogenesis and neuronal maturation and also increase BDNF activity, which can develop the antidepressant response. Figure 1 represents these effects of neuronal plasticity or BDNF on major depression, antidepressant treatment, and suicide behavior. BDNF could play an important role in the modulation of neuronal networks. Such neuronal plastic change can positively influence mood or recover depressed mood. These alterations of BDNF levels or neuro- 


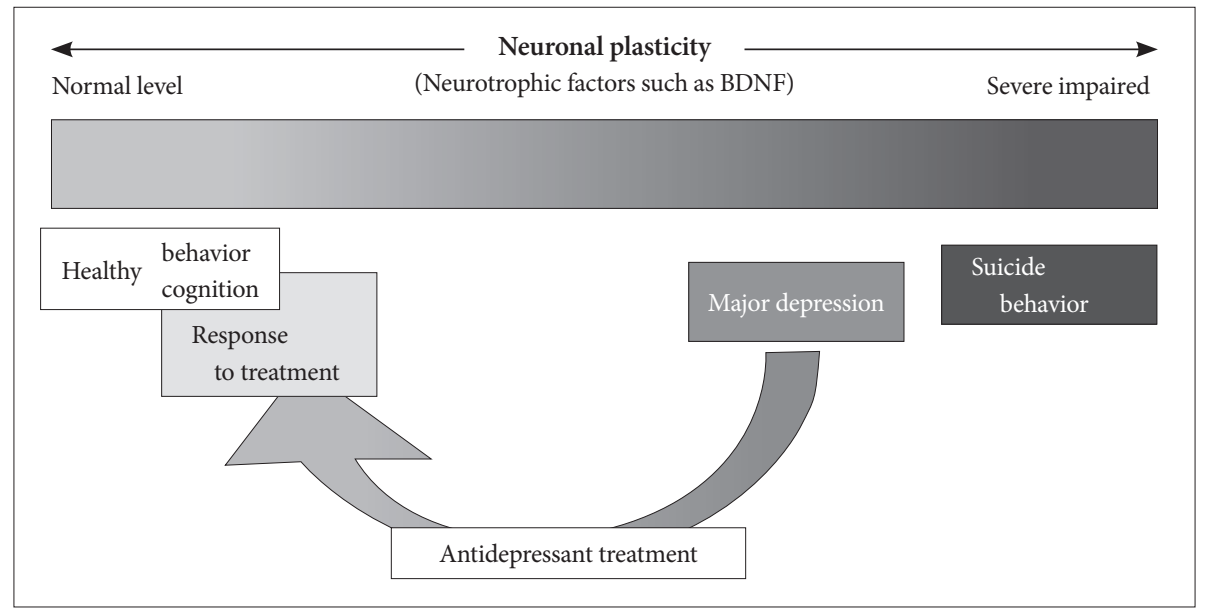

Figure 1. The neuronal plasticity in major depression, antidepressant treatment, and suicide behavior. Major depression is associated with impaired neuronal plasticity in the brain. Suicide behavior can be a consequence of very severe impaired neuronal plasticity. Antidepressant treatments promote several forms of neuronal plasticity, including neurogenesis, synaptogenesis and neuronal maturation together with increasing brain-derived neurotrophic factor activity, which can develop the antidepressant response. The neuronal plastic change can influence mood or recover depressed mood.

nal plasticity in MDD patients before and after antidepressant treatment can be measured through serum or plasma BDNF concentrations. BDNF levels in serum or plasma will be useful markers for clinical response or improvement of depressive symptoms rather than a diagnostic marker of major depression.

\section{REFERENCES}

1. Warner-Schmidt JL, Duman RS. Hippocampal neurogenesis: opposing effects of stress and antidepressant treatment. Hippocampus 2006;16: 239-249.

2. Mellstrom B, Torres B, Link WA, Naranjo JR. The BDNF gene: exemplifying complexity in $\mathrm{Ca} 2+-$ dependent gene expression. Crit Rev Neurobiol 2004;16:43-49.

3. Lu B, Pang PT, Woo NH. The yin and yang of neurotrophin action. Nat Rev Neurosci 2005;6:603-614.

4. Miller FD, Kaplan DR. Neurotrophin signaling pathways regulating neuronal apoptosis. Cell Mol Life Sci 2001;58:1045-1053.

5. Duman RS. Pathophysiology of depression: the concept of synaptic plasticity. Eur Psychiatry 2002;17 Suppl 3:306-310.

6. Castrén E, Võikar V, Rantamäki T. Role of neurotrophic factors in depression. Curr Opin Pharmacol 2007;7:18-21.

7. Smith MA, Makino S, Kvetnansky R, Post RM. Stress and glucocorticoids affect the expression of brain-derived neurotrophic factor and neurotrophin-3 mRNAs in the hippocampus. J Neurosci 1995;15:1768-1777.

8. Ueyama T, Kawai Y, Nemoto K, Sekimoto M, Toné S, Senba E. Immobilization stress reduced the expression of neurotrophins and their receptors in the rat brain. Neurosci Res 1997;28:103-110.

9. Rasmusson AM, Shi L, Duman R. Downregulation of BDNF mRNA in the hippocampal dentate gyrus after re-exposure to cues previously associated with footshock. Neuropsychopharmacology 2002;27:133-142.

10. Pizarro JM, Lumley LA, Medina W, Robison CL, Chang WE, Alagappan A, et al. Acute social defeat reduces neurotrophin expression in brain cortical and subcortical areas in mice. Brain Res 2004;1025:10-20.

11. Roceri M, Hendriks W, Racagni G, Ellenbroek BA, Riva MA. Early maternal deprivation reduces the expression of BDNF and NMDA receptor subunits in rat hippocampus. Mol Psychiatry 2002;7:609-616.

12. Russo-Neustadt A, Ha T, Ramirez R, Kesslak JP. Physical activity-antidepressant treatment combination: impact on brain-derived neurotro- phic factor and behavior in an animal model. Behav Brain Res 2001;120: 87-95.

13. Schaaf MJ, de Jong J, de Kloet ER, Vreugdenhil E. Downregulation of BDNF mRNA and protein in the rat hippocampus by corticosterone. Brain Res 1998;813:112-120.

14. Dwivedi Y, Rizavi HS, Pandey GN. Antidepressants reverse corticosterone-mediated decrease in BDNF expression: dissociation in regulation of specific exons by antidepressants and corticosterone. Neuroscience 2006;139:1017-1029.

15. Chao HM, Sakai RR, Ma LY, McEwen BS. Adrenal steroid regulation of neurotrophic factor expression in the rat hippocampus. Endocrinology 1998;139:3112-3118.

16. Tsankova NM, Berton O, Renthal W, Kumar A, Neve RL, Nestler EJ. Sustained hippocampal chromatin regulation in a mouse model of depression and antidepressant action. Nat Neurosci 2006;9:519-525.

17. Duman RS, Monteggia LM. A neurotrophic model for stress-related mood disorders. Biol Psychiatry 2006;59:1116-1127.

18. Müller MB, Toschi N, Kresse AE, Post A, Keck ME. Long-term repetitive transcranial magnetic stimulation increases the expression of brainderived neurotrophic factor and cholecystokinin mRNA, but not neuropeptide tyrosine mRNA in specific areas of rat brain. Neuropsychopharmacology 2000;23:205-215.

19. Altar CA, Laeng P, Jurata LW, Brockman JA, Lemire A, Bullard J, et al. Electroconvulsive seizures regulate gene expression of distinct neurotrophic signaling pathways. J Neurosci 2004;24:2667-2677.

20. Balu DT, Hoshaw BA, Malberg JE, Rosenzweig-Lipson S, Schechter LE, Lucki I. Differential regulation of central BDNF protein levels by antidepressant and non-antidepressant drug treatments. Brain Res 2008; 1211:37-43.

21. Coppell AL, Pei Q, Zetterström TS. Bi-phasic change in BDNF gene expression following antidepressant drug treatment. Neuropharmacology 2003;44:903-910.

22. De Foubert G, Carney SL, Robinson CS, Destexhe EJ, Tomlinson R, Hicks $\mathrm{CA}$, et al. Fluoxetine-induced change in rat brain expression of brainderived neurotrophic factor varies depending on length of treatment. Neuroscience 2004;128:597-604.

23. Altieri M, Marini F, Arban R, Vitulli G, Jansson BO. Expression analysis of brain-derived neurotrophic factor (BDNF) mRNA isoforms after chronic and acute antidepressant treatment. Brain Res 2004;1000:148-155.

24. Hajszan T, MacLusky NJ, Leranth C. Short-term treatment with the antidepressant fluoxetine triggers pyramidal dendritic spine synapse for- 
mation in rat hippocampus. Eur J Neurosci 2005;21:1299-1303.

25. Sairanen M, O’Leary OF, Knuuttila JE, Castrén E. Chronic antidepressant treatment selectively increases expression of plasticity-related proteins in the hippocampus and medial prefrontal cortex of the rat. Neuroscience 2007;144:368-374.

26. Saarelainen T, Hendolin P, Lucas G, Koponen E, Sairanen M, MacDonald E, et al. Activation of the TrkB neurotrophin receptor is induced by antidepressant drugs and is required for antidepressant-induced behavioral effects. J Neurosci 2003;23:349-357.

27. Monteggia LM, Barrot M, Powell CM, Berton O, Galanis V, Gemelli T, et al. Essential role of brain-derived neurotrophic factor in adult hippocampal function. Proc Natl Acad Sci U S A 2004;101:10827-10832.

28. Altar CA, Whitehead RE, Chen R, Wörtwein G, Madsen TM. Effects of electroconvulsive seizures and antidepressant drugs on brain-derived neurotrophic factor protein in rat brain. Biol Psychiatry 2003;54:703-709.

29. MacQueen GM, Ramakrishnan K, Croll SD, Siuciak JA, Yu G, Young LT, et al. Performance of heterozygous brain-derived neurotrophic factor knockout mice on behavioral analogues of anxiety, nociception, and depression. Behav Neurosci 2001;115:1145-1153.

30. Zörner B, Wolfer DP, Brandis D, Kretz O, Zacher C, Madani R, et al. Forebrain-specific trkB-receptor knockout mice: behaviorally more hyperactive than "depressive". Biol Psychiatry 2003;54:972-982.

31. Chen B, Dowlatshahi D, MacQueen GM, Wang JF, Young LT. Increased hippocampal BDNF immunoreactivity in subjects treated with antidepressant medication. Biol Psychiatry 2001;50:260-265.

32. Dowlatshahi D, MacQueen GM, Wang JF, Young LT. Increased temporal cortex CREB concentrations and antidepressant treatment in major depression. Lancet 1998;352:1754-1755.

33. Fujimura H, Altar CA, Chen R, Nakamura T, Nakahashi T, Kambayashi J, et al. Brain-derived neurotrophic factor is stored in human platelets and released by agonist stimulation. Thromb Haemost 2002;87:728-734.

34. Pan W, Banks WA, Fasold MB, Bluth J, Kastin AJ. Transport of brainderived neurotrophic factor across the blood-brain barrier. Neuropharmacology 1998;37:1553-1561.

35. Poduslo JF, Curran GL. Permeability at the blood-brain and blood-nerve barriers of the neurotrophic factors: NGF, CNTF, NT-3, BDNF. Brain Res Mol Brain Res 1996;36:280-286.

36. Gonul AS, Akdeniz F, Taneli F, Donat O, Eker C, Vahip S. Effect of treatment on serum brain-derived neurotrophic factor levels in depressed patients. Eur Arch Psychiatry Clin Neurosci 2005;255:381-386.

37. Karege F, Perret G, Bondolfi G, Schwald M, Bertschy G, Aubry JM. Decreased serum brain-derived neurotrophic factor levels in major depressed patients. Psychiatry Res 2002;109:143-148.

38. Karege F, Bondolfi G, Gervasoni N, Schwald M, Aubry JM, Bertschy G. Low brain-derived neurotrophic factor (BDNF) levels in serum of depressed patients probably results from lowered platelet BDNF release unrelated to platelet reactivity. Biol Psychiatry 2005;57:1068-1072.

39. Shimizu E, Hashimoto K, Okamura N, Koike K, Komatsu N, Kumakiri C, et al. Alterations of serum levels of brain-derived neurotrophic factor (BDNF) in depressed patients with or without antidepressants. Biol
Psychiatry 2003;54:70-75.

40. Lee BH, Kim H, Park SH, Kim YK. Decreased plasma BDNF level in depressive patients. J Affect Disord 2007;101:239-244.

41. Brunoni AR, Lopes M, Fregni F. A systematic review and meta-analysis of clinical studies on major depression and BDNF levels: implications for the role of neuroplasticity in depression. Int J Neuropsychopharmacol 2008;11:1169-1180.

42. Yoshimura R, Mitoma M, Sugita A, Hori H, Okamoto T, Umene W, et al. Effects of paroxetine or milnacipran on serum brain-derived neurotrophic factor in depressed patients. Prog Neuropsychopharmacol Biol Psychiatry 2007;31:1034-1037.

43. Matrisciano F, Bonaccorso S, Ricciardi A, Scaccianoce S, Panaccione I, Wang L, et al. Changes in BDNF serum levels in patients with depression disorder (MDD) after 6 months treatment with sertraline, escitalopram, or venlafaxine. J Psychiatr Res 2009;43:247-254.

44. Lee HY, Kim YK. Plasma brain-derived neurotrophic factor as a peripheral marker for the action mechanism of antidepressants. Neuropsychobiology 2008;57:194-199.

45. Piccinni A, Marazziti D, Catena M, Domenici L, Del Debbio A, Bianchi $\mathrm{C}$, et al. Plasma and serum brain-derived neurotrophic factor (BDNF) in depressed patients during 1 year of antidepressant treatments. J Affect Disord 2008;105:279-283.

46. Dwivedi Y, Rizavi HS, Conley RR, Roberts RC, Tamminga CA, Pandey $\mathrm{GN}$. Altered gene expression of brain-derived neurotrophic factor and receptor tyrosine kinase B in postmortem brain of suicide subjects. Arch Gen Psychiatry 2003;60:804-815.

47. Pandey GN, Ren X, Rizavi HS, Conley RR, Roberts RC, Dwivedi Y. Brainderived neurotrophic factor and tyrosine kinase $\mathrm{B}$ receptor signalling in post-mortem brain of teenage suicide victims. Int J Neuropsychopharmacol 2008;11:1047-1061.

48. Ernst C, Deleva V, Deng X, Sequeira A, Pomarenski A, Klempan T, et al. Alternative splicing, methylation state, and expression profile of tropomyosin-related kinase B in the frontal cortex of suicide completers. Arch Gen Psychiatry 2009;66:22-32.

49. Dwivedi Y, Rizavi HS, Zhang H, Mondal AC, Roberts RC, Conley RR, et al. Neurotrophin receptor activation and expression in human postmortem brain: effect of suicide. Biol Psychiatry 2009;65:319-328.

50. Deveci A, Aydemir O, Taskin O, Taneli F, Esen-Danaci A. Serum BDNF levels in suicide attempters related to psychosocial stressors: a comparative study with depression. Neuropsychobiology 2007;56:93-97.

51. Kim YK, Lee HP, Won SD, Park EY, Lee HY, Lee BH, et al. Low plasma BDNF is associated with suicidal behavior in depression. Prog Neuropsychopharmacol Biol Psychiatry 2007;31:78-85.

52. Dawood T, Anderson J, Barton D, Lambert E, Esler M, Hotchkin E, et al. Reduced overflow of BDNF from the brain is linked with suicide risk in depressive illness. Mol Psychiatry 2007;12:981-983.

53. Malcangio M, Lessmann V. A common thread for pain and memory synapses? Brain-derived neurotrophic factor and trkB receptors. Trends Pharmacol Sci 2003;24:116-121. 